https://doi.org/10.47370/2078-1024-2021-13-3-115-122

УДК 378: $159.9(060.55)$

Николаев М.В.

ГРАЖДАНСКОЕ ВОСПИТАНИЕ УЧАЩЕЙСЯ МОЛОДЕЖИ В УСЛОВИЯХ ЦИФРОВИЗАЦИИ И ИНФОРМАТИЗАЦИИ СИСТЕМЫ ОБРАЗОВАНИЯ

\author{
Николаев Михаил Васильевич, \\ кандидат педагогических наук, дочент, докторант, научный сотрудник \\ ГОУ ВО МО «Московский государственный областной университет», \\ Мьттищи, Россия; \\ e-mail:sem.kur@mail.ru, \\ тел.: +7 (917) 5856676
}

\begin{abstract}
Аннотация
В наше время сложились предпосылки воспитания подрастающего поколения в условиях цифровизации общества. Это означает, что происходят изменения в социальных, экономических и политических сферах жизни, что влечет за собой изменения в методике преподавания и воспитания подрастающего поколения. Активное применение цифровых технологий в гражданском воспитании обучающихся создает высокотехнологичную среду проживания, что обусловливает воспитание компетентных и конкурентоспособных цифровых граждан. В этих условиях расширяются возможности образования и воспитания учащихся с учетом индивидуальных особенностей. Обозначенное подчеркивает актуальность проблемы информатизации общества и внедрения информационных технологий в процесс гражданского воспитания учащейся молодежи.

Проблема исследования заключается в информатизации общества и пироком использовании информационных систем в процессе гражданского воспитания подрастающего поколения.

Цель исследования: обозначить актуальные вопросы гражданского воспитания в учебно-воспитательном процессе учебного заведения в условиях цифровизации и информатизации общества.

Методы исследования: анализ, синтез, индукция, дедукция, обобщение.

Результаты исследования: представлено обобщенное определение понятия гражданского воспитания в условиях цифровизации; показаны способы применения мультимедийных технологий в воспитательном процессе; описаны телекоммуникационные проекты для решения задач гражданского воспитания; описаны социально-психологические установки подрастающего поколения, формируемые в процессе использования цифровых технологий.

Ключевые выводы: информационные системы имеют высокий воспитательный потенциал, так как обеспечивают доступность и качество формирования гражданских ценностей учащейся молодежи на расстоянии; средствами гражданского воспитания могут быть интернет-ресурсы; воспитательная работа в условиях цифровизации общества является технологичным процессом; для воспитания цифровых граждан нужен соответствующий педагогический инструментарий; мультимедийные технологии позволяют прививать учащимся гражданские ценности воспитания.
\end{abstract}


Ключевые слова: гражданское воспитание, информатизация культуры, массовая культуpa, культура гражданского поведения, комплекс гражданских ценностей, воспитание цифровых граждан и патриотов, информационные системы, цифровые технологии, интернет-блоги, формирование личности «цифровых» граждан.

Для цитировапия: Николаев МВ. Гражданское воспитапие учащейся молодежи в условиях иифровизачии и информатизации системы образования// Вестник Майкопского государственного технологического университета. 2021. Том 13, № 3. C. 115-122. https:/doi.org/10.47370/2078-1024-2021-13-3-115-122.

\title{
Nicolaev M.V. \\ CIVIC EDUCATION OF STUDENTS IN THE CONDITIONS OF DIGITALIZATION AND INFORMATIZATION OF THE EDUCATION SYSTEM
}

\author{
Nicolaev Mikhail Vasilievich, \\ Candidate of Pedagogy, an associate professor, a doctoral student, a researcher, \\ Moscow State Regional University, Mytishchi, Russia; \\ e-mail:sem.kur@mail.ru, \\ tel.: +7 (917) 5856676
}

\section{Annotation}

Nowadays the preconditions for the upbringing of the younger generation in the context of the digitalization of society have emerged. This means that changes are taking place in the social, economic and political spheres of life, which entails changes in the methods of teaching and upbringing of the younger generation. The active use of digital technologies in civic education of students creates a high-tech living environment, which leads to the education of competent and competitive digital citizens. In these conditions, the possibilities of education and upbringing of students are expanding, taking into account individual characteristics. The aforementioned emphasizes the relevance of the problem of informatization of society and the introduction of information technologies in the process of civic education of students.

The research problem lies in the informatization of society and the widespread use of information systems in the process of civic education of the younger generation.

The purpose of the research is to identify topical issues of civic education in the educational process of an educational institution in the context of digitalization and informatization of society.

The research methods used are analysis, synthesis, induction, deduction, generalization.

The research results: a generalized definition of the concept of civic education in the context of digitalization has been presented; the ways of using multimedia technologies in the educational process have been shown; telecommunication projects for solving problems of civic education and social and psychological attitudes of the younger generation have been described.

Key conclusions: information systems have a high educational potential, as they ensure the availability and quality of the formation of civic values among students at a distance; Internet resources can be the means of civic education; educational work, in the context of the digitalization of society, is a technological process; education of digital citizens requires appropriate pedagogical tools; multimedia technologies allow to instill in students the civic values of education.

Keywords: civic education, informatization of culture, mass culture, culture of civic behavior, complex of civic values, education of digital citizens and patriots, information systems, digital technologies, Internet blogs, formation of a personality of "digital" citizens 
For citation: Nikolaev MV. Civic education of students in the conditions of digitalization and informatization of the education system "/ Vestnik Majkopskogo gosudarstvennogo tehnologiceskogo universiteta. 2021. Volume 13, No. 3. P. 115-122. https:/doi. org/10.47370/2078-1024-2021-13-3-115-122.

В настоящее время происходят изменения в процессе воспитательной деятельности, так как идет информатизация культуры. Следовательно, происходят изменения в образовательной системе, меняется социальный заказ общества, меняется педагогический инструментарий, что в конечном счете требует изменений в методике преподавания и воспитания подрастающего поколения. Условия жизни требуют вести подрастающее поколение и готовить его к жизни в социальных, экономических и политических сферах жизни. Меняется массовая культура, которая ориентирована на удовлетворение запросов большинства населения в потреблении стандартизированных продуктов, прежде всего, интеллектуальной деятельности [1]. Процессы глобализации обусловливают информатизацию, которая, как нам известно, создает условия, удовлетворяющие потребности человека в получении новой информации. Сказанное актуализирует проблему информатизации общества и широкого использования информационных систем в процессе гражданского воспитания подрастающего поколения.

Информационные системы обладают высоким воспитательным потенциалом, и поэтому их использование с ориентацией на массовую аудиторию имеет важное значение. Целью формирования культуры гражданского поведения является расширение педагогического инструментария для развития гражданственности личности [2].

Современная учащаяся молодежь в условиях цифровизации получает широкий доступ к информационным средствам, что способствует более глубокому развитию личности. Их становление происходит во время широкого распространения цифровых систем, поэтому им приходится развивать в себе цифровые компетенции, а также иметь представления об использовании различных устройств и электронных программ. Другими словами, создается высокотехнологичная среда проживания, в которой необходимо развивать учащихся с учетом их индивидуальности, воспитывая личность с компетенциями, соответствующими современной жизни, и соответственно являющимися конкурентоспособными специалистами [6]. В настоящее время современный педагог-воспитатель, выполняя роль консультанта, помогает учащимся в процессе обучения, для оптимального поиска нужной информации.

Цифровизация учебно-воспитательного процесса расширяет образовательные возможности и дает учащимся возможность работать самостоятельно, опираясь на свои интеллектуальные и творческие способности. В условиях активной цифровизации расширяются образовательные возможности учащихся, но есть другая сторона - воспитательная работа, которая испытывает определенные трудности [5]. Воспитательная работа в условиях цифровизации общества вызывает много вопросов, таких как: 1) в какой форме должна быть организована воспитательная работа; 2) быть ли воспитательному процессу технологичным; 3) направить ли ее на взаимодействие и приобщение к труду и другие.

Каким же образом определяется воспитательная работа в современном информационном пространстве, а точнее, каковы особенности гражданского воспитания личности? Существует множество определений гражданского воспитания. Некоторые ученые отождествляют процесс воспитания с процессом 
социализации, который предполагает вхождение человека в общество, в нашем случае - в информационное общество. Обобщая определения, относительно гражданского воспитания мы можем его определить как целенаправленное и постоянное воздействие на обучающихся с целью формирования личности, полезной обществу.

В Федеральном законе «Об образовании в Российской Федерации» в части «О внесении изменений в Федеральный закон «Об образовании в Российской Федерации〉 в статье 2 , п. 2 по вопросам воспитания обучающихся отмечается, что воспитание - это «деятельность, направленная на развитие личности, создание условий для самоопределения и социализации обучающегося на основе социокультурных, духовно-нравственных ценностей и принятых в обществе правил и норм поведения в интересах человека, семьи, общества и государства» [8]. Следовательно, необходимо создавать благоприятные условия для развития обучающихся, в нашем случае - для формирования гражданских ценностей в цифровом обществе - с помощью таких инструментов, которые способствовали бы гражданскому воспитанию.

В распоряжении Правительства РФ от 29 мая 2015 г. № 996-р «Стратегия развития воспитания в Российской Федерации на период до 2025 года) в пункте «Основные направления развития воспитания) отмечается, что в формировании целостной личности необходимо развивать такую личность, которая будет обладать нравственными качествами, включающими ценности нашего государства, быть конкурентоспособной в условиях современного общества и способной к созиданию и защите Родины [7]. Речь идет о воспитании цифровых граждан и патриотов.

По нашему мнению, гражданское воспитание в условиях современной России - это формирование личности, связанное с повышением ее общественной роли, общественного лица, разделяющего государственные ценности, и необходимость развития информационного общества, в котором каждый индивид чувствует себя полноценным членом. Информационные ресурсы расширяют воспитательные возможности, так как они предполагают создание методов и технологий для гражданского воспитания учащихся.

Следующей задачей является информационное обеспечение воспитательной деятельности, а также представление в информационном пространстве традиционных российских культурных, и в том числе гражданских качеств. Кроме того, необходимо учить подрастающее поколение правильно выбирать нужную информацию и разбираться в информации, причиняющей вред психическому и физическому здоровью [4].

В процессе гражданского воспитания широко используются мультимедийные технологии разных видов (для общего и индивидуального пользования; для профессионалов и рядовых потребителей; интерактивная информация на месте или на расстоянии), с помощью которых создаются продукты с текстом, данными, изображениями, сопровождающиеся звуком, видео, анимацией, и несущие в себе информативно-воспитательный потенциал [3]. В контексте становления гражданственности у обучающихся появляются возможности виртуально посещать оперу и театр, знакомиться с историческими фильмами, общаться с известными гражданами нашего государства, что способствует эффективному формированию гражданских ценностей.

Применение элементов мультимедийных технологий в воспитательном процессе способствует тому, что учащиеся запоминают государственную символику оформления и у них в сочетании с картинками вызываются определенные чувства, эмоции, ассоциации, вследствие чего обучающийся может познать и 
понять технологии не только на обыденном уровне, но и чувственном. С помощью мультимедийных технологий могут прививаться нравственные ценности воспитания. Учащиеся имеют возможность посещать культовые места, изучать тексты и т.д. Кроме того, мультимедийные технологии позволяют отображать информацию, что способствует повышению наглядности воспитательного процесса, то есть соблюдается принцип наглядности воспитания [6]. Это всё вызывает у обучающихся интерес к обсуждаемой проблеме, создает мотивационный фон для осознанного восприятия воспитанниками представленной информации.

Для развития интереса обучающихся к проблеме формирования гражданственности могут быть использованы телекоммуникационные технологии (телефонная связь, радиосвязь, спутниковая связь, интернет), которые дают возможность обучающимся работать совместно со сверстниками в интернет-проектах, имеющих большой образовательный и воспитательный потенциал. В процессе использования названных технологий у воспитанников развиваются такие качества личности, как культура общения, толерантные отношения, уважение к педагогам и сверстникам.

Телекоммуникационные (совокупность алгоритмов, программных средств для пакета информации, аудио- и видеоинформации) проекты в контексте решения задач гражданского воспитания способствуют самоопределению, самореализации и самосовершенствованию учащихся, также помогают развивать умение самостоятельно и критически мыслить, создавать новые идеи, творчески мыслить, грамотно работать с информацией, развивать коммуникативные способности, усваивать условия жизни в социуме с целью развития гражданских ценностей. В учебно-воспитательном процессе телекоммуникационные проекты могут пополняться политико-правовым содержанием, оказывающим влияние на формирование гражданской воспитанности [5].

Кроме воспитания гражданственности использование информационных технологий позволяет решить и другие воспитательные задачи. Одной из них является информационная культура личности, которая понимается как совокупность знаний и представлений, которыми личность овладевает в процессе работы в информационном обществе. Информационная культура личности - это не только накопление преимуществ, но и осознание негативных влияний современных информационных ресурсов. Современные учащиеся при помощи педагога могут выделять полезную информацию и использовать ее для саморазвития и самосовершенствования, будучи гражданином своей страны.

Кроме данной информации, считаем необходимым отметить тот факт, что технологические открытия оказывают влияние на систему гражданского воспитания в целом. Современные технологии формируют требования к навыкам и компетенциям граждан нашей страны, а это в свою очередь связано с подготовкой педагогических работников с цифровыми компетенциями, что влечет за собой необходимость развивать конкурентоспособность образовательных учреждений. Цифровизация развивается с огромной скоростью, и на это оказывает влияние всё более расширяющаяся доступность интернета и информационных технологий для людей. Высокая скорость развития информационных технологий приводит к дальнейшему повышению доступности информационных технологий [2]. Технологические факторы, кроме всего прочего, имеют и экономическую основу. Цифровизация учебно-воспитательного процесса оказывает влияние на социально-психологические установки подрастающего поколения, которые в своем большинстве предпочитают 
цифровые технологии, поэтому основным источником информации для них становиться интернет. Многие страны, в том числе и Россия, переходят в настоящее время на цифровую экономику. А это влечет за собой перестройку всей системы образования, меняются ценности, в том числе гражданские. Знания и навыки становятся в этих условиях основным ресурсом для обеспечения конкурентоспособных цифровых граждан. Цифровизация общества предполагает цифровизацию образования и воспитания, а это означает расширение образовательного и воспитательного пространства.

Образование и воспитание уже не ограничены рамками образовательного учреждения. Рынок труда требует высокого качества подготовки специалистов, цифровые знания и навыки становятся необходимой компетенцией для подрастающего поколения. В этих условиях стираются различия, имеющие значение в индустриальный период, и образовательные учреждения на всех уровнях вынуждены конкурировать друг с другом.

Если говорить об управлении системы образования, то нужно отметить, что в настоящее время автоматизируются трудоемкие процессы. Также нужно отметить, что цифровые технологии позволяют отслеживать динамику усвоения учащимися учебных знаний и поведенческих аспектов. И в данном случае воспитательный потенциал цифровых технологий дает возможность отслеживать поведение не всех участников, допустим группы, а поведение каждого, то есть мы сталкиваемся с технологиями, способствующими оптимизации учебновоспитательного процесса на индивидуальном уровне. Речь идет о создании индивидуальной траектории персонифицированного обучения и воспитания каждого конкретного учащегося. Учебно-образовательное пространство расширяется за счет массовых открытых онлайн-курсов, вместо обычного дистанционного формата образования $[9 ; 10 ; 11 ; 12]$. Появляется возможность виртуализации воспитательного процесса, внедрения технологий виртуальной реальности, включающей в себя комплекс гражданских ценностей для формирования личности «цифровых» граждан. Цифровизация воспитания расширяет масштабы влияния этого процесса на все возможные сферы общества, и в этом отношении складывающаяся цифровая система гражданского воспитания имеет преимушества над классической системой воспитания. Недостатком цифровой системы воспитания нам представляется временная ограниченность подготовки, то есть скорость воспитания, а из классической теории нам известно, что формирование гражданских ценностей занимает продолжительное время в соответствии с возрастными и психологическими особенностями учащихся. Онлайн-подготовка в этом плане уступает классическому воспитанию, поэтому наряду с использованием цифровых технологий, по нашему мнению, есть необходимость сохранить подлинное «аналоговое) богатство технологии гражданского воспитания учащихся.

Подводя итоги, отметим, что активная цифровизация оказывает влияние на организацию воспитательной работы и пересматривает подходы к этой деятельности. Цифровизация общества - это неизбежный процесс, следовательно, любые виды воспитательной деятельности, в том числе и формирование гражданственности, не могут обойтись без цифровых технологий. В условиях цифровизации многие мероприятия, такие как онлайн-трансляции, виртуальные экскурсии, встречи с интересными людьми становятся доступными. Для педагогов появляются дополнительные возможности в использовании цифровых технологий, но, тем не менее, есть смысл сохранить технологии классического гражданского воспитания учащихся и использовать их в сочетании с цифровыми. 


\section{ЛИТЕРАТУРА:}

1. Нравственное воспитание на рубеже тысячелетий: проблемы, поиски, решения // Материалы Всероссийской научной конференции. Карачаевск, 2004. 230 с.

2. Поддубная Т.Н. Некоторые аспекты цифровизации современного образования // Непрерывное образование в России: состояние и перспективы: материалы докладов X Всероссийской научно-практической конференции. Ростов н/Д: РостГМУ, 2020. С. 245-249.

3. Разенкова Н.Е., Рукавицина Е.Д. Системно-деятельностный подход в организации педагогических практик студентов высших профессиональных учебных заведений // Сибирский педагогический журнал. 2010. № 7. С. 167-181.

4. Сазонова В.В., Фирсова Е.Ю., Крылова О.Ю. К проблеме профориентации выпускников специальной (коррекционной) школы // Перспективы науки. Тамбов. 2019. № 2 (113). С. 181-191.

5. О проблемах поиска путей цифровизации образовательной среды вуза / Семенов К.Б. [и др.] // Вестник Сургутского государственного педагогического университета. 2020. № 4 (67). C. $133-141$.

6. Семенов К.Б. Об активизации познавательной деятельности личности // Вестник Университета (ГУУ). 2011. № 25. С. 57-60.

7. Основные направления развития воспитания. Стратегия развития воспитания в Российской Федерации на период до 2025 года: Распоряжение Правительства РФ от 29 мая 2015 г. № 996-р.

8. О внесении изменений в Федеральный закон «Об образовании в Российской Федерации» по вопросам воспитания обучающихся: Проект Федерального закона.

9. Deublein Andrea et al. Scaffolding of motivation in learning using a social robot // Computers \& Education. 2018. Vol. 125. P. 182-190.

10. Stylianos Sergis Investigating the impact of Flipped Classroom on students' learning experiences: A SelffDetermination Theory approach // Computers in Human Behavior. 2018. Vol. 78. P. $368-378$.

11. Yilmaz R. Exploring the role of e-learning readiness on student satisfaction and motivation in flipped classroom // Computers in Human Behavior. 2017. Vol. 70. P. 251-260.

12. Zainuddin Z. Students' learning performance and perceived motivation in gamified flippedclass instruction // Computers \& Education. 2018. Vol. 126. P. 75-88.

\section{REFERENCES:}

1. Moral education at the turn of the millennium: problems, searches, solutions // Materials of the All-Russian Scientific Conference. Karachaevsk, 2004. 230 p.

2. Poddubnaya T.N. Some aspects of digitalization of modern education // Continuing education in Russia: state and prospects: materials of reports of the X All-Russian scientific and practical conference. Rostov n/D: RostSMU, 2020. P. 245-249.

3. Razenkova N.E., RukavitsinaE.D. A system-activity approach in the organization of pedagogical practices of students of higher professional educational institutions // Siberian pedagogical journal. 2010. No. 7. P. $167-181$.

4. Sazonova VIV., Firsova E.Yu., Krylova O.Yu. On the problem of vocational guidance of graduates of a special (correctional) school // Prospects for Science. Tambov. 2019. No. 2 (113). P. 181-191.

5. On the problems of finding ways to digitalize the educational environment of a university /. Semenov K.B. [et al.] // Bulletin of the Surgut State Pedagogical University. 2020. No. 4 (67) P. $133-141$.

6. Semenov K.B. On the activation of a person's cognitive activity // Bulletin of the University (GUU). 2011. No. 25. P. 57-60. 
7. The main directions of development of education. Strategy for the development of education in the Russian Federation for the period up to 2025: Order of the Government of the Russian Federation dated May 29, 2015. No. 996-r.

8. On the amendments to the Federal Law "On the Education in the Russian Federation" on the education of students: Draft Federal Law.

9. Deublein Andrea et al. Scaffolding of motivation in learning using a social robot// Computers \& Education. 2018. Vol. 125. P. 182-190.

10. Stylianos Sergis Investigating the impact of Flipped Classroom on students 'learning experiences: A Self-Determination Theory approach // Computers in Human Behavior. 2018. Vol. 78. P. 368-378.

11. Yilmaz R. Exploring the role of e-learning readiness on student satisfaction and motivation in flipped classroom // Computers in Human Behavior. 2017. Vol. 70. P. 251-260.

12. Zainuddin Z. Students 'learning performance and perceived motivation in gamified flippedclass instruction // Computers \& Education. 2018. Vol. 126. P. 75-88. 